\title{
REVIEW.
}

\section{A SHORT HISTORY OF SOME COMMON DISEASES}

\section{By divers Authors.}

By W. R. BetT, M.R.C.S., L.R.C.P., Oxf. Univ. Press. London. Humphry Milford. 1934. Price 10/6.

In these strenuous days of materialism, when art is, perhaps, hardly so long as it was and life seems even shorter, it is with a pleasant sense of calm and refreshment that we have read this charming account of the gradual progress of medicine in the face of some of the well-known diseases, and have rejoiced in the human element which is so beautifully reflected in it. The teaching of history is always a difficult matter. Hard, dry facts, which must form its basis, if the lesson is to be of any real value, are apt to weary us unless the manner of presentation is such that we can readily bring them into relation with everyday life as we know it. There is so much in this book which enables us to do so that we welcome it as a pleasant oasis in the arid desert of scientific medicine, and we recommend it to our readers as a gentle stimulus to their search for knowledge.

The chapters are all short, and therefore necessarily give no more than a précis of the history of the diseases of which they treat. To some this may seem a defect, to others an advantage. The impression which we gained from the book as a whole was that it was designed rather to give a preface to the study of medical history than to supply an account which could make any pretence at completeness. As an introduction to this aspect of medicine it is excellent in that it serves to arouse the reader's curiosity and to urge him to digr further and more deeply into this field. If this be the object of the Editor and of the Publishers, and such we conceive it to be, they have certainly succeeded. It would be invidious to single out any of the essays for special comment. They are all by wellknown writers, masters of their subject; several of them bear the stamp of the author's personality which adds to their intrinsic charm. Examples are afforded of the clinical descriptions of common diseases given by the ancient writers. These are arresting, and of no little value, for they show what power and accuracy of observation was possessed by these men, who had but their own natural faculties upon which to depend for information. It is interesting to reflect upon some of the earlier methods of treatment, the efficacy of which was often recognised by such pioneers, although the rationale was unknown to them. One great feature of the book is that it is a study in intuition. Throughout the history of men's errors and of the gradual development of knowledge therefrom can be traced the instinctive perception of light and truth which has been the basis of much of the best work and of most advances in medicine. It is, perhaps, the intention of the Editor to show us this point. This at least is what we feel he is hinting at in the exquisite dedication of the volume to those illusions which have in perpetuity enriched his life, and on which, in so far as they have assisted him in the production of this delightful symposium, he is to be warmly congratulated.

\section{Miscellaneous.}

There is nothing new in the discovery of valerian. It was employed in neurological Anglo-French Drug Co. Ltd. practice by the Greek and Roman schools of medicine. Elixir Bromo - Valerianate (Gabail), distributed by the Anglo-French Drug Co., of 11/12, Guilford Street, W.C.1, is described as the ideal sedative in all nervous affections. According to Dr. J. S. Manson, in the British Medical Journal of November 10,1928 - "Valerian is a very useful drug in general practice, capable of restoring mental efficiency and alleviating mental misery. It has also the advantage of having no deleterious properties such as are associated with the habit-forming narcotic series of drugs"'.

The dried root from which valerian is prepared has an unpleasant taste and odour. In Elixir Bromo-Valerianate Gabail this is not merely disguised but completely removed, without the addition of any chemical whatsoever. 